\title{
An Affine Projection Algorithm based Adaptive Control Scheme for Operation of Variable-Speed Wind Generator
}

\author{
${ }^{1}$ Hany M. Hasanien, and ${ }^{2}$ S.M. Muyeen \\ ${ }^{1}$ Electrical Power and Machines Department, Faculty of Engineering, Ain Shams University, \\ Cairo 11517, Egypt (e-mail:hanyhasanien@ieee.org) \\ ${ }^{2}$ Department of Electrical Engineering, The Petroleum Institute, Abu Dhabi 2533, United Arab \\ Emirates
}

Abstract - This paper presents a novel adaptive control scheme for variable-speed wind turbine (VSWT) driven permanent magnet synchronous generator (PMSG) to ensure its operation under different operating conditions. The adaptive control scheme is based on the affine projection algorithm (APA) which provides a faster convergence and less computational complexity than the least-mean-square algorithm. The proposed adaptive controller is used to control both the generatorside converter and the grid-side inverter without giving additional tuning efforts. Each vector control scheme for the converter/inverter has four APA-based adaptive proportional-integral (PI) controllers. Detailed modeling and the control strategies of the system under study are demonstrated. Real wind speed data extracted from Hokkaido island, Japan is used in this study. The dynamic characteristics of a grid-connected VSWT-PMSG are investigated in details to ensure the proposed controller operation under different operating conditions. The effectiveness of the proposed adaptive controller is compared with that obtained using optimized PI controllers by Taguchi method. The validity of the adaptive vector control scheme is verified by the simulation results which are performed using PSCAD/EMTDC environment.

Index Terms-Affine projection algorithm, permanent magnet synchronous generator, PI controller, Taguchi method, variable-speed wind turbine, vector control scheme. 


\section{INTRODUCTION}

$\mathrm{T}^{\mathrm{H}}$ are many factors affecting the high level of penetration of the wind power into electric grids worldwide such as increase in fuel price, probability of fuel depletion, environmental concerns, and trend to a clean energy. The global wind power installations reached $282.5 \mathrm{GW}$ at the end of 2012 and the cumulative market growth is closer to $19 \%$ [1]. Based on the statistics of Global Wind Energy Council, it is expected that the wind power will contribute to $12 \%$ of the total world electricity by 2020 [2]. As a result of the high level of penetration of the wind power into the electric grids, many problems arise in the electric power systems. These problems should be addressed, studied, and investigated. Therefore, it is needed to analyze the dynamic characteristics of the grid-connected wind turbine generation system.

The variable-speed wind generators are used extensively in the market, where they have better control, lower quantities ripple, and less mechanical stress than the fixed-speed wind generators. Different types of electrical generators have been used as variable-speed wind generators such as a doubly fed induction generator (DFIG) [3], [4], permanent magnet synchronous generator (PMSG) [5]-[7], and switched reluctance generator [8], [9]. The PMSGs have multi magnetic poles and large air gaps. Therefore, low rotational generator speed can be achieved and the gearbox is canceled resulting in lower cost and losses [10].

The variable-speed wind turbine (VSWT) direct drive PMSG system is connected to the power grid through a full-scale frequency converter which usually consists of back-to-back converters connected to a common DC-link. Generally, the vector controller is used to control the generator-side converter and the grid-side inverter. In this control strategy, the vector controller is substantially based on the conventional proportional-integral (PI) controllers which offer a wide stability margin. However, these controllers are sensitive to parameters variation and system nonlinearity. Several methods have been used to properly fine tuned the PI controllers in the electric power systems [11]-[18]. Recently, in our previous study, genetic algorithms with the help of response surface methodology has been successfully applied to optimally design the PI controllers in outer loops of the vector control scheme of the grid-side inverter with the purpose of enhancing fault ride through of the VSWT-PMSG system [19]. Moreover, in [20], a Taguchi method is utilized in fine tuning the PI controllers in both inner and outer loops of the control scheme of the 
grid-side inverter to improve transient stability of a grid-connected VSWT-PMSG system. From these reported works, it can be noted that it is difficult to optimally design all the PI controllers of the control schemes of both the generator-side converter and the grid-side inverter at the same time, where each vector control scheme contains four PI controllers. Furthermore, if any optimization technique is able to optimally design eight PI controllers in such heavy nonlinear system, a complex computational analysis will be performed, a long time will be taken, and a great effort should be exerted. This represents the main motivation to the authors to use adaptive PI controllers in this application. In this study, adaptive PI controllers are based on the affine projection algorithm (APA) and they are used in the vector control scheme of the generator-side converter and the grid-side inverter.

The APA is an adaptive filtering algorithm derived from the conventional least-mean-square (LMS) algorithm. It was introduced by Ozeki and Umeda [21]. The main merit of the APA is its capability for providing faster convergence than the LMS algorithm. In addition, it has less computational analysis than the Kalman filter and the recursive least square algorithms. The APA has been applied to solve different engineering problems [22]-[24].

This paper presents the development of an adaptive control scheme to ensure a good dynamic performance of a grid-connected VSWT-PMSG under different operating conditions. The adaptive vector control scheme is based on the APA. The proposed controller is used to control both the generator-side converter and the grid-side inverter. Each vector control scheme for the converter/inverter has four APAbased adaptive PI controllers. Detailed modeling and the control strategies of the system under study are investigated. Real wind speed data extracted from Hokkaido island, Japan is used in this study. The effectiveness of the proposed controller is compared with that obtained using optimized PI controllers by Taguchi method. The validity of adaptive control scheme is verified by the simulation results which are performed using PSCAD/EMTDC environment. With the proposed controller, the additional tuning efforts for the PI controllers used in frequency converter of VSWT-PMSG can be omitted and an optimum operation of the wind generator can be ensured.

The paper is organized as follows: Section II describes the wind turbine model. In Section III, the model system is introduced. Section IV presents the control strategy of the frequency converter. In Section V, the APA technology is extensively described. Section VI presents the simulation results and discussion. 
Finally, Section VII draws the conclusion.

\section{Wind TURbINe MODEL}

The mechanical power generated from the wind turbine, $\mathrm{P}_{\mathrm{wt}}$, is proportional to the cube of the wind speed, $\mathrm{V}_{\mathrm{w}}$ and can be expressed by the following equation [25]-[31]:

$$
\mathrm{P}_{\mathrm{wt}}=0.5 \rho \mathrm{AV}_{\mathrm{w}}^{3} \mathrm{C}_{\mathrm{P}}(\lambda, \beta)
$$

where $\rho$ is the air density, $A=\pi R^{2}$ is the area swept by wind turbine blades of radius $R$. The power coefficient, $C_{p}$ can be related to turbine blade pitch angle, $\beta$ and tip speed ratio, $\lambda$ and it can be expressed by the following equations [32]:

$$
\begin{gathered}
\lambda=\frac{\omega_{r} R}{V_{W}} \\
L_{i}=\frac{1}{\frac{1}{(\lambda+0.02 \beta)}-\frac{0.03}{\left(\beta^{3}+1\right)}} \\
C_{P}(\lambda, \beta)=0.73\left\{\frac{151}{L_{i}}-0.58 \beta-0.002 \beta^{2.14}-13.2\right\} e^{\frac{-18.4}{L_{i}}}
\end{gathered}
$$

where $\omega_{\mathrm{r}}$ is the rotational speed of the shaft.

The VSWT generation system is becoming more popular compared with the fixed-speed wind turbine system because of its ability to maximize the captured power from the same wind speed conditions. Any wind speed and a specific turbine speed, can ensure maximum active power extraction from the wind. This phenomena is commonly known as maximum power point tracking (MPPT) scheme and using this option, the VSWT generation system increases energy generation from cut-in to the rated wind speed conditions. In this study, the wind turbine characteristics used in the wind turbine model are shown in Fig. 1 along with the trajectory of maximum point.

It is cumbersome to sense the wind speed accurately and hence, in some cases, preferable to calculate the maximum power using the rotor speed using the following equation [32]:

$$
P_{\text {max }}=0.5 \rho A\left(\frac{\omega_{r} R}{\lambda_{o p t}}\right)^{3} C_{p-o p t}
$$

where $\mathrm{C}_{\mathrm{p}_{-} \text {opt }}$ is the optimum power coefficient and $\lambda_{\text {opt }}$ is the optimum tip speed ratio. This maximum power is used as the power set-point at the frequency converter, either in the generator-side converter or the grid- 
side inverter. In case of the rotor speed is higher than the rated speed of the wind turbine, the mechanical pitch angle controller activates as reported in [33] to keep the rotor speed constant at the rated speed.

In some VSWT generation systems, the drive train is fully decoupled from the power grid due to the presence of the frequency converter in between the generator and the grid. Therefore, the drive train complexity can be avoided in the case of VSWT driven PMSG [34].

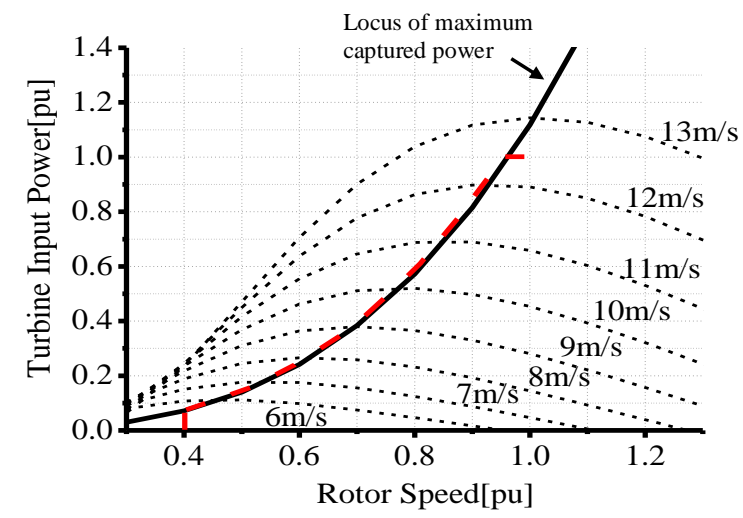

Fig. 1. Wind turbine characteristics with MPPT.

\section{MODEL SySTEM}

A simple model system shown in Fig. 2 is considered in this study to demonstrate the effectiveness of the adaptive control scheme applied to the frequency converter of the VSWT driven PMSG. The system model consists of a wind turbine, PMSG, two power converters connected back-to-back, a step up transformer, and a transmission line. The data of the PMSG are shown in Table I. The system base is considered as 5 MVA.

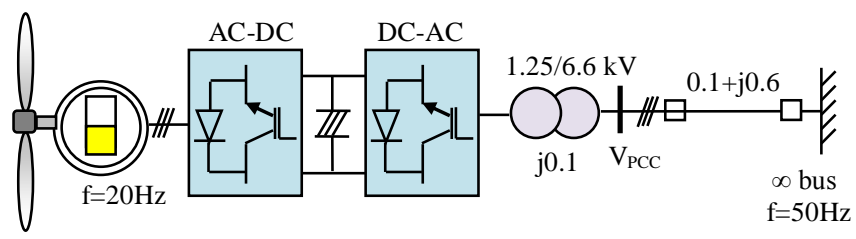

Fig. 2. System model. 
TABLE I

GENERATOR DATA

\begin{tabular}{|c|c|c|c|}
\hline \multicolumn{5}{|c|}{ GENERATOR DATA } \\
\hline Rated power & $5 \mathrm{MW}$ & Stator resistance & $0.01 \mathrm{pu}$ \\
\hline Rated voltage & $1.0 \mathrm{kV}$ & d-axis reactance & $1.0 \mathrm{pu}$ \\
\hline Frequency & $20 \mathrm{~Hz}$ & q-axis reactance & $0.7 \mathrm{pu}$ \\
\hline Poles & 150 & Magnetic flux & $1.4 \mathrm{pu}$ \\
\hline $\mathrm{H}$ & $3.0 \mathrm{~s}$ & & \\
\hline
\end{tabular}

\section{Control of Frequency Converter}

The frequency converter used in grid-interconnection of a VSWT driven PMSG has two converters connected back-to-back with intermediate DC-link. The control of the back-to-back converters is explained briefly in the following subsections:

\section{1) Generator-Side Converter}

In this study, the generator-side converter is responsible to extract maximum possible power from the wind turbine and transmit the power towards the electric grid. To meet the requirement, a vector control scheme is usually preferred where the q-axis current is controlled to control the active power with a setpoint $\left(\mathrm{P}_{\mathrm{opt}}\right)$ calculated from the MPPT scheme. The stator current d-axis component is used to control the reactive power. In this case, the reactive power set-point ( $\mathrm{Q}_{\text {ref-pmsg }}$ ) is set to zero for unity power factor operation at the generator terminals. The proposed control scheme for the generator-side converter is shown in Fig. 3. It can be noted that four adaptive PI controllers (PI-1 to PI-4) are utilized to produce the dq components of the reference voltage $\left(\mathrm{V}_{\text {dref }}\right.$ and $\left.\mathrm{V}_{\text {qref }}\right)$. These components are transformed to the abc frame $\left(\mathrm{V}_{\text {ref-a,b,c }}\right)$ using the transformation angle $\left(\theta_{\mathrm{r}}\right)$ which can be extracted from the generator speed $\left(\omega_{\mathrm{r}}\right)$. The $\mathrm{V}_{\text {ref-a,b,c }}$ signals are compared with a triangular carrier waveform signal to generate the firing pulses to the converter insulated gate bipolar transistor (IGBT) switches. The chosen frequency of the carrier signal is 1 kHz. 


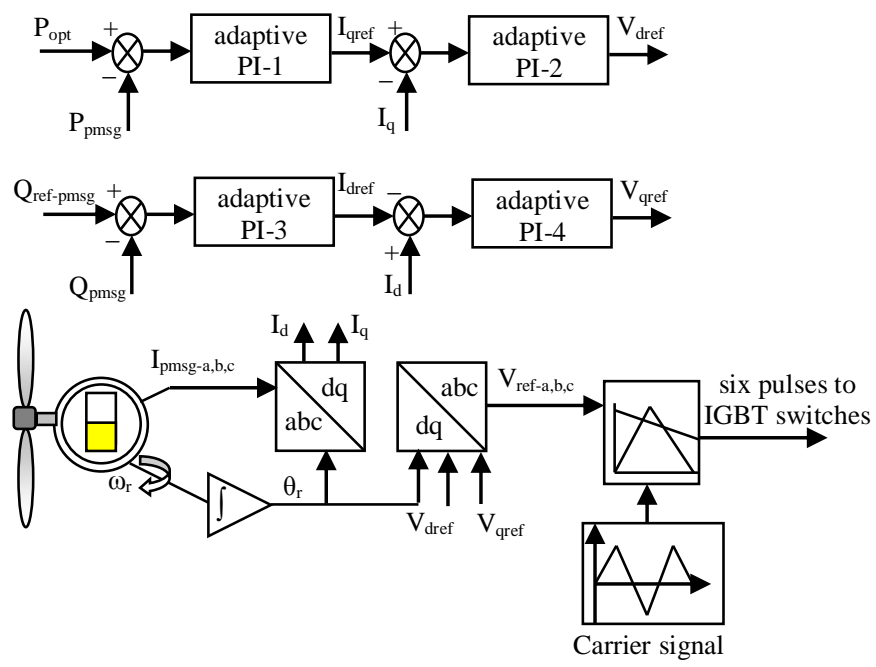

Fig. 3. Control block diagram of the generator-side converter.

\section{2) Grid-Side Inverter}

The grid-side inverter operation is carried out using the conventional vector control scheme where the DC-link voltage $\left(\mathrm{V}_{\mathrm{DC}}\right)$ can be controlled by the d-axis current. In this study, the temporary energy buffer, the DC-link capacitor value is set as $10000 \mu \mathrm{F}$. The DC-link rated voltage is considered as $2.3 \mathrm{kV}$. The q-axis current is used to control the terminal voltage at the point of common coupling (PCC) that located on the high voltage side of the transformer, shown in Fig. 2. The proposed control scheme for the grid-side inverter is shown in Fig. 4. Also, four adaptive PI controllers (PI-5 to PI-8) are used to generate $\mathrm{V}_{\text {dref }}$ and $\mathrm{V}_{\text {qref. }}$. Here, these components are transformed to $\mathrm{V}_{\text {ref-a,b,c }}$ using the transformation angle $\left(\theta_{\mathrm{t}}\right)$. The three-phase voltages, $\mathrm{V}_{\mathrm{PCC}}$, are the input signals to the phase locked loop (PLL) and its output signal represents $\theta_{\mathrm{t}}$. The $\mathrm{V}_{\text {ref-a,b,c }}$ signals are compared with a triangular carrier waveform signal to generate the firing pulses to the inverter IGBT switches. The chosen frequency of the carrier signal is $1050 \mathrm{~Hz}$. All the adaptive PI controllers are based on the APA technology. The mathematical model and analysis of the APA-based adaptive PI controller is explained in details in the next section. 


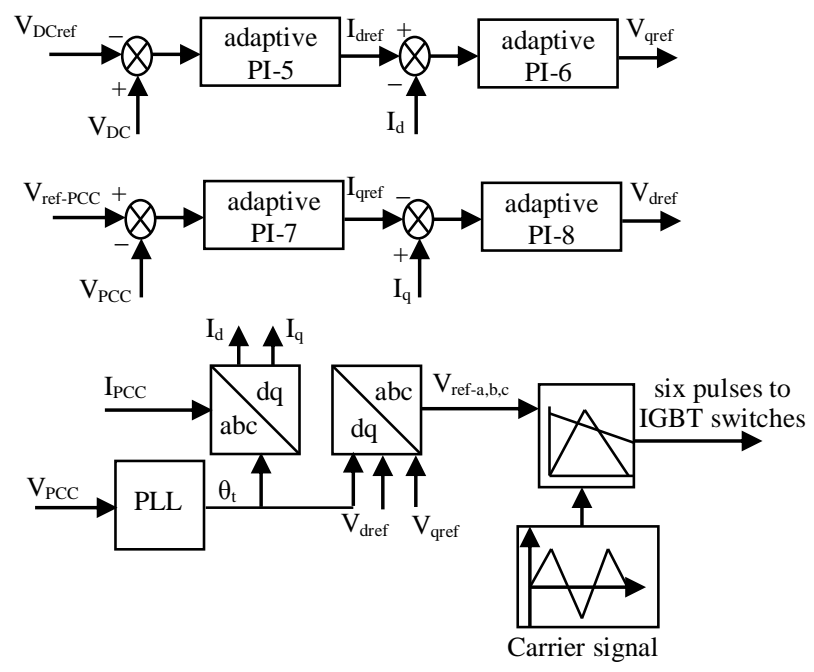

Fig. 4. Control block diagram of the grid-side inverter.

\section{THE APA}

The APA is an adaptive filtering algorithm derived from the conventional LMS algorithm. The basic idea of the APA was presented by Ozeki and Umeda [21]. The main advantage of the APA is its capability for providing faster convergence than the LMS algorithm. However, it requires higher computational cost than the LMS algorithm. In addition, it has less computational analysis than the Kalman filter and the recursive least square algorithms.

The APA reuses old data, resulting in faster convergence than that of the normalized LMS that uses only the current data. The APA expedites the convergence speed where the input signal is correlated. This leads to different types of the APA algorithms that can trade-off computational complexity with convergence speed [35].

The main vectors that can be defined in the APA algorithm at a given iteration $k$, are expressed as follows:

$$
\begin{gathered}
y(k)=x^{T}(k) w(k) \\
e(k)=d(k)-y(k)
\end{gathered}
$$

where $y(k)$ is the output vector of the adaptive filter, $x(k)$ is an input signals vector, $d(k)$ is the desired signal vector, and $e(k)$ is the error signal vector [36]. 
The target of the APA is to minimize

$$
\begin{gathered}
\frac{1}{2}\|w(k+1)-w(k)\|^{2} \\
\text { subject to: } \\
d(k)=x^{T}(k) w(k+1)
\end{gathered}
$$

The APA can maintain the next coefficient vector $w(k+1)$ as close to the current vector $w(k)$ and forcing the posterior error to be zero. The vector $w(k+1)$ can be written by the following equation:

$$
w(k+1)=w(k)+\mu x(k)\left(x^{T}(k) x(k)+\gamma I\right)^{-1} e(k)
$$

where $\mu$ is the reduction factor that chosen in the range $0<\mu \leq 2$, and $\gamma$ is a small constant value.

In this study, the efficient APA is used to update the proportional gain $\left(k_{p}\right)$ and the integral gain $\left(k_{i}\right)$ of the PI controllers in each vector control scheme. The update of these gains can be described by the following formulas:

$$
\begin{aligned}
& k_{p}(k+1)=k_{p}(k)+\Delta k_{p} \\
& k_{i}(k+1)=k_{i}(k)+\Delta k_{i}
\end{aligned}
$$

The online adaptation of the controller parameters depends mainly on equation (9). The input vector $x(k)$ equals $[m(k-1), e(k)-e(k-1), e(k)+e(k-1)]^{\mathrm{T}}$ where $m(k-1)$ is one step previous output of the PI controller. The current coefficient vector $w(k)=\left[1, k_{p}(k), k_{i}(k)\right]^{\mathrm{T}}$. Fig. 5 shows the block diagram of the APA-based adaptive PI controller. The difference between the reference signal $\left(\mathrm{U}_{\mathrm{ref}}(\mathrm{k})\right)$ and the actual signal $(\mathrm{U}(\mathrm{k}))$ is the error signal $e(k)$. These two input signals to the summing point are varied according to the adaptive PI controller location in each control scheme. For example, for adaptive PI-1, shown in Fig. 3, $\mathrm{U}_{\text {ref }}(\mathrm{k})$ and $\mathrm{U}(\mathrm{k})$ are $\mathrm{P}_{\mathrm{opt}}$ and $\mathrm{P}_{\mathrm{pmsg}}$, respectively, and the controller output $\mathrm{m}(\mathrm{k})$ represents the reference $\mathrm{q}$-axis current $\left(\mathrm{I}_{\mathrm{qref}}\right)$. 


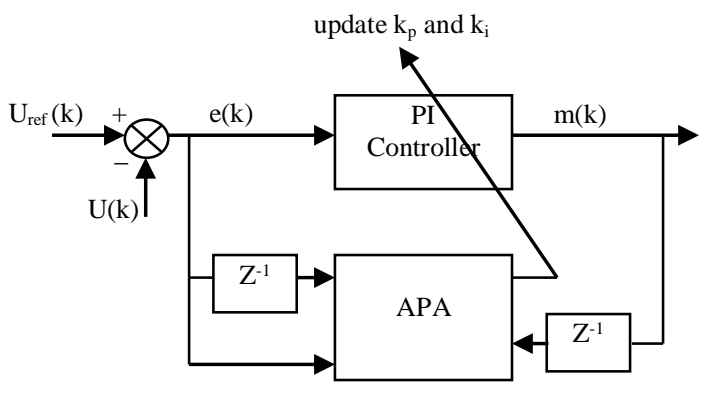

Fig. 5. Block diagram of the APA-based adaptive PI controller.

\section{Vi. Simulation Results}

The simulation results have been performed by using PSCAD/EMTDC environment [37]. Time step for the simulation is considered $0.00002 \mathrm{~s}$. The dynamic performance of the proposed controller is tested with two conditions that are explained as follows:

\section{1) Test Condition-1}

In this case, a user defined wind speed pattern, shown in Fig. 6 (a), is used. The reference power for the generator-side converter is generated as explained in Section II and is shown with green color in Fig. 6 (b). The grid-side real power using Taguchi optimized PI controllers [20] and the proposed adaptive control scheme are also indicated in the same graph. It is seen that both approaches give almost similar results under different operating conditions. The difference between the reference power and the grid-side real power is due to the losses of the two converters and the transformer. In this test condition, the responses of the generator speed, the grid reactive power, the terminal voltage $\mathrm{V}_{\mathrm{PCC}}$, and the DC-link voltage are also monitored using both schemes as shown in Figs. 6 (c)-6 (f). It is noted that these responses are pretty similar. 


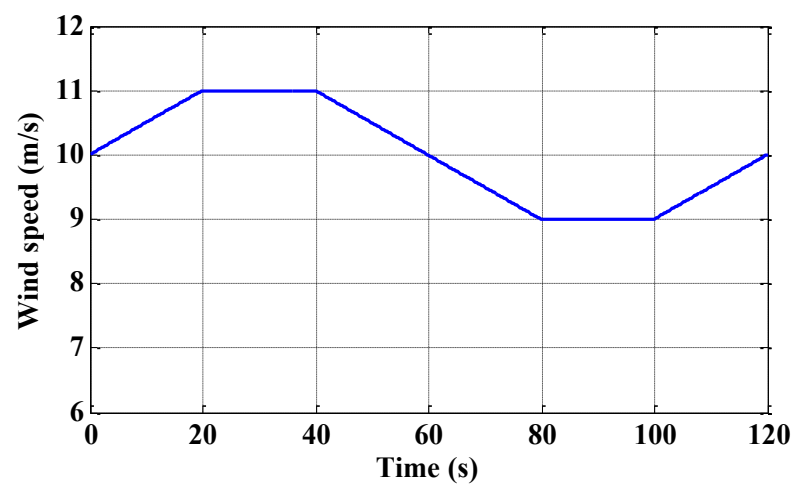

(a)

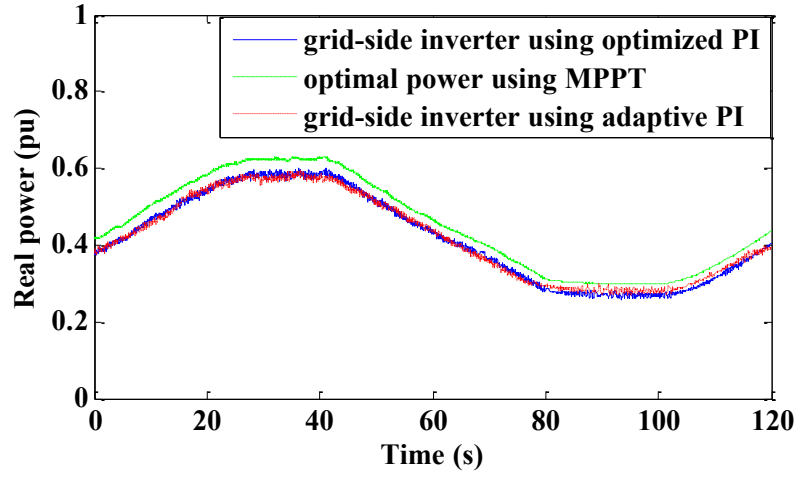

(b)

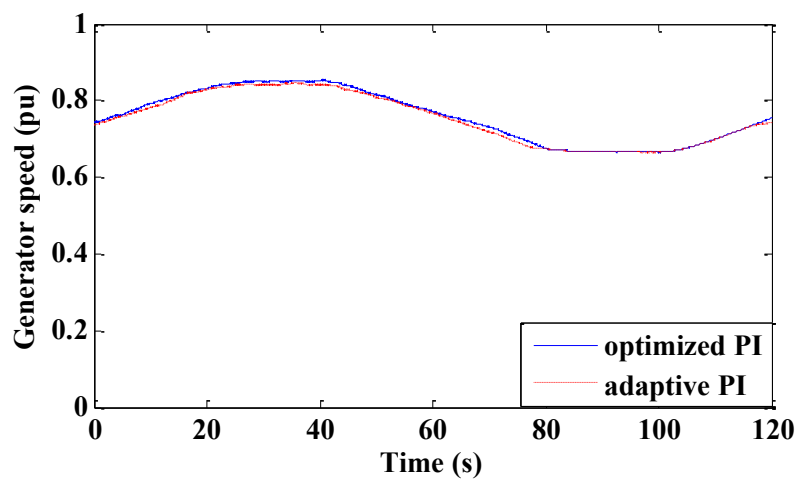

(c)

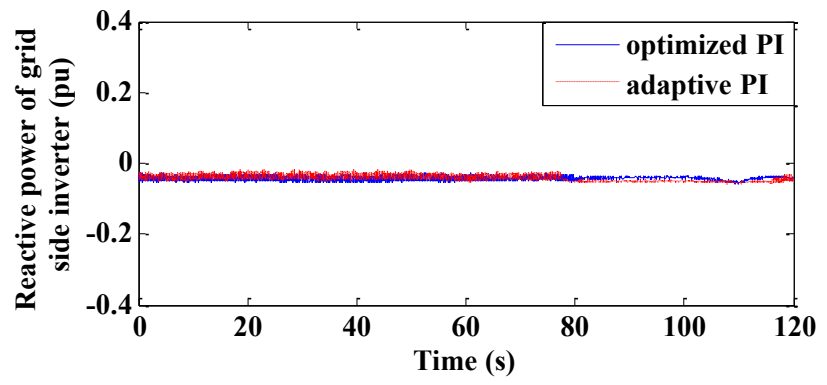

(d) 


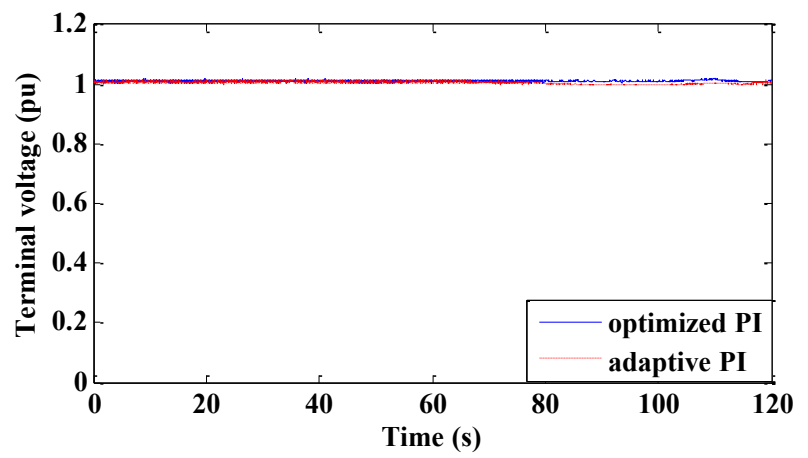

(e)

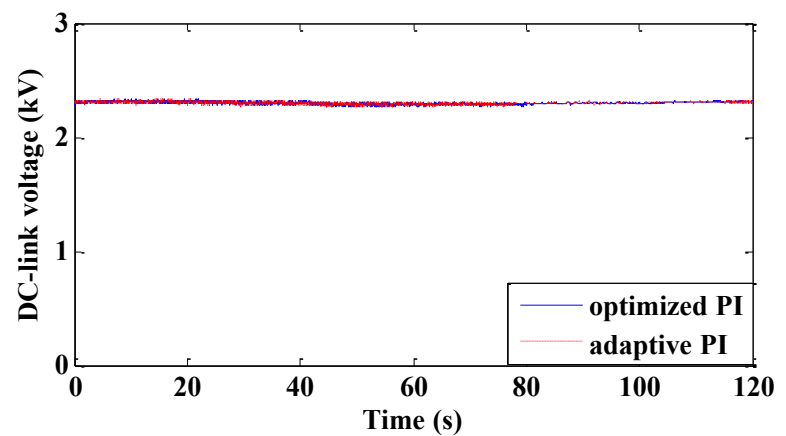

(f)

Fig. 6. Responses for a comparison between optimized PI and adaptive PI controllers (a) Wind speed. (b) PMSG speed. (c) Real power of the grid-side inverter. (d) Reactive power of the grid-side inverter. (e) Terminal voltage at the PCC. (f) DC-link voltage.

\section{2) Test Condition-2}

In this test case, a real wind speed pattern, shown in Fig. 7 (a), that is measured in Hokkaido Island, Japan, is considered to verify the dynamic performance of VSWT-PMSG. Time step and simulation time are $0.00002 \mathrm{~s}$ and $600 \mathrm{~s}$, respectively. It can be noted that during this 10 minutes pattern, the wind speed varies from $8.5 \mathrm{~m} / \mathrm{s}$ to $14.8 \mathrm{~m} / \mathrm{s}$ to indicate a wide range of the wind speed pattern used in this study. The rated wind speed is $12.4 \mathrm{~m} / \mathrm{s}$. The responses of the generator speed, the turbine blade pitch angle, the real \& optimum power to the power grid, the grid reactive power, the terminal voltage $\mathrm{V}_{\mathrm{PCC}}$, and the DClink voltage are shown in Figs. 7 (b) -7 (g). It is found that the proposed controller can extract the maximum power in all operating conditions despite the sharp and deeply wind speed variation. Moreover, it is able to maintain the grid-side terminal voltage and keeping the DC-link voltage constant. Figs. 7 (h) and (i) indicate the variation of the proportional and integral gains of PI-7, which controls $\mathrm{V}_{\text {PCC. As can be seen }}$ from these figures, the controller gains are updated continuously online by the proposed adaptive algorithm so as to minimize the error signal in an expedite way and efficiently track the desired signal. To guarantee 
the stability of the system and avoiding the divergence of the proposed controllers, the initial values of the controllers parameters should be selected carefully by the designer. Therefore, the proposed adaptive control scheme is an effective means to adapt the PI controllers' parameters of the frequency converter when the operating conditions change randomly. In addition, the proposed control technique eliminates the cumbersome tuning efforts to fine tune the eight PI controllers of the two vectors controlled converters.

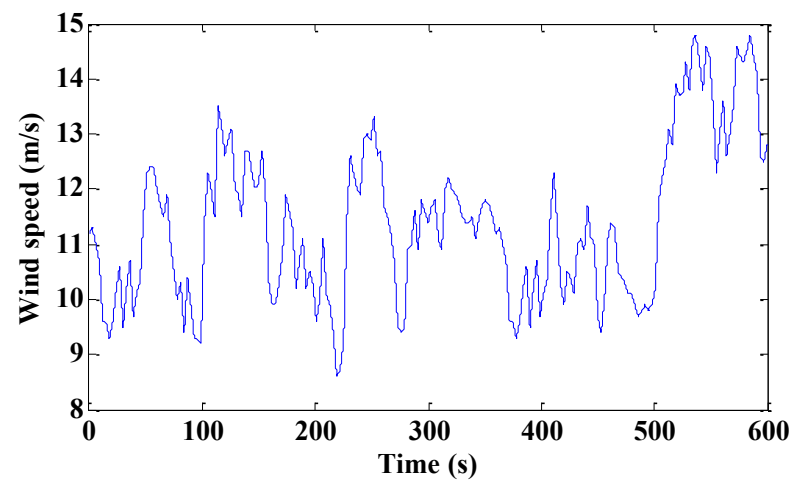

(a)

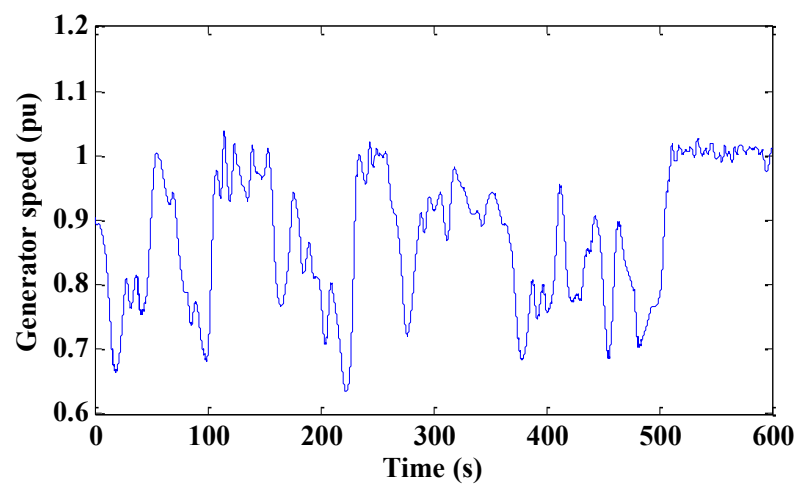

(b)

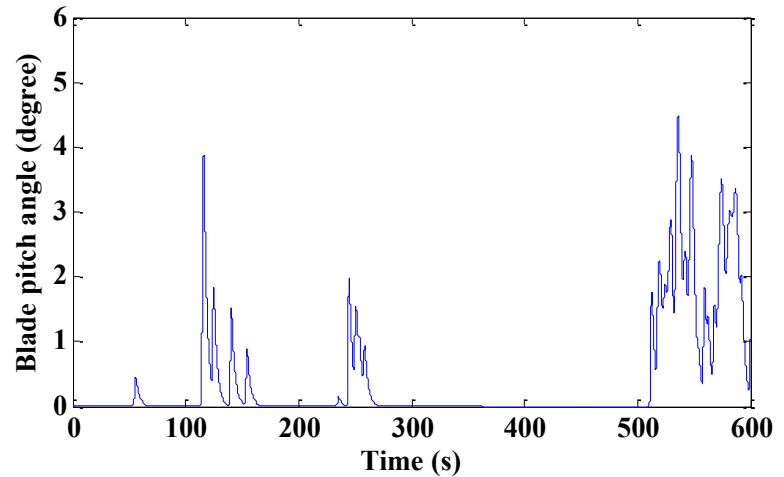

(c) 


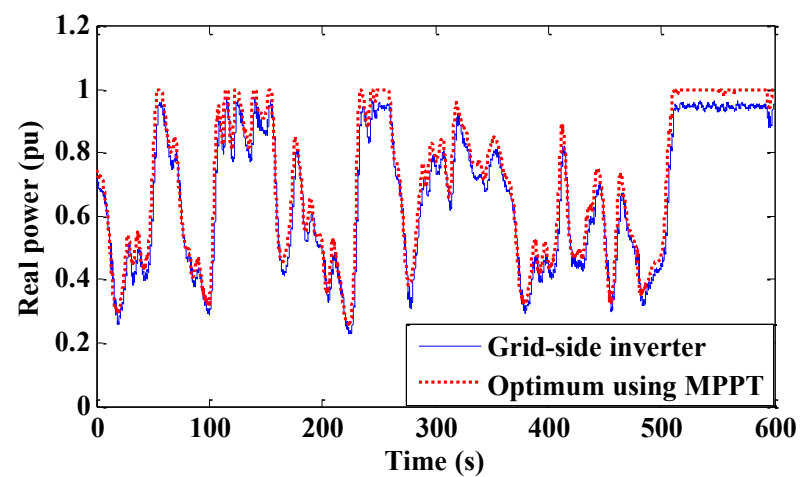

(d)

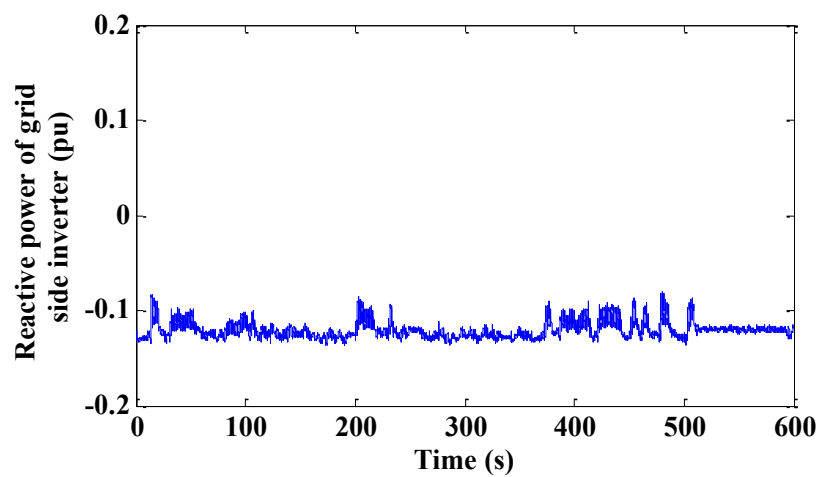

(e)

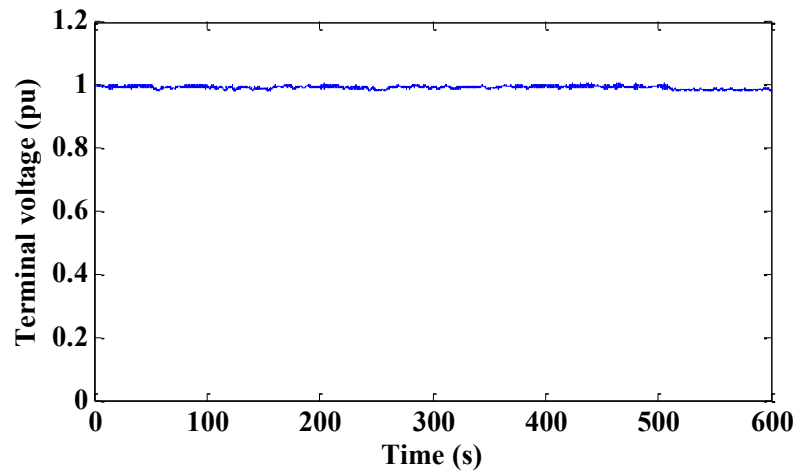

(f)

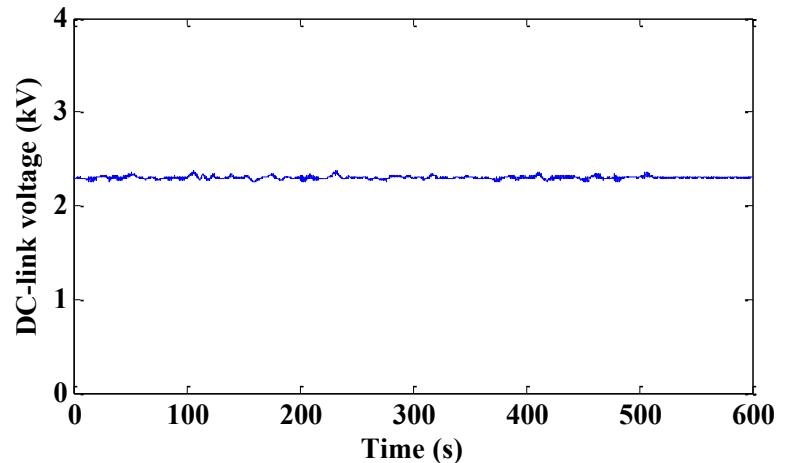

(g) 


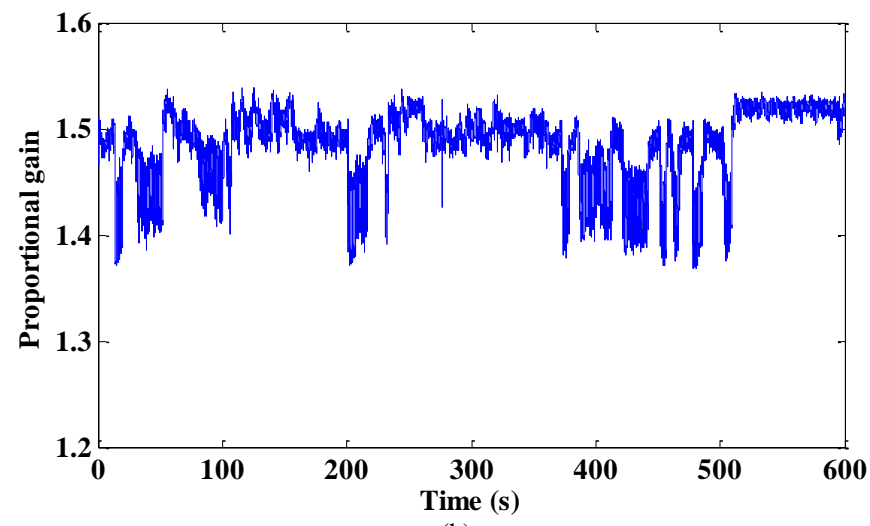

(h)

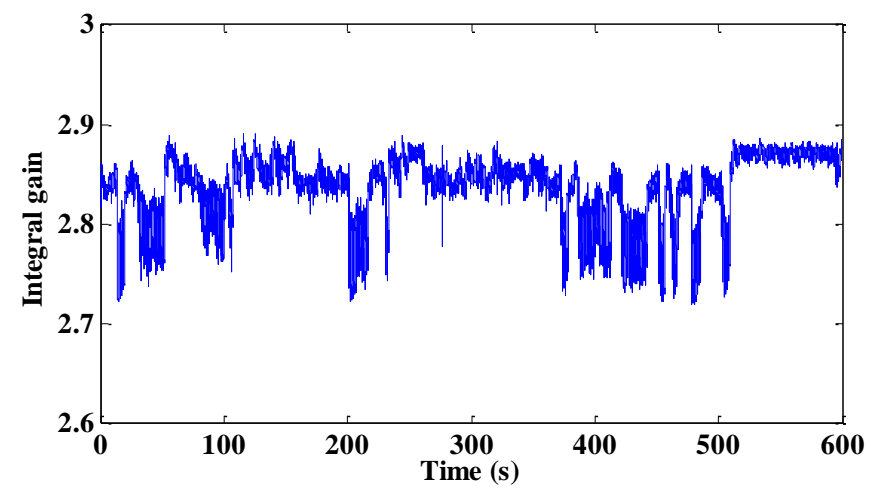

(i)

Fig. 7. Responses for adaptive PI controllers using real wind speed data (a) Wind speed. (b) PMSG speed. (c) Blade pitch angle. (d) Real power of the grid-side inverter. (e) Reactive power of the grid-side inverter. (f) Terminal voltage at the PCC. (g) DC-link voltage. (h) Proportional gain. (i) Integral gain.

\section{Conclusion}

This study attempts to develop tuning effortless control scheme for the frequency converter of variablespeed wind turbine driven wind generator. The proposed control scheme can efficiently operate under different operating conditions. In that context, the affine projection algorithm based adaptive control scheme is developed for vector control of the frequency converter. The dynamic performance of the proposed controller is tested using a predefined pattern and considering real wind speed conditions. It is found that the proposed adaptive controller works very well in the aforementioned conditions and the results are pretty similar in comparison with that obtained using the Taguchi approach based optimized controller parameters. The proposed adaptive technique works perfectly with the complex non-linear system that its mathematical model is difficult to achieve and hence the tuning of controller parameters is cumbersome. 


\section{REFERENCES}

[1] Global Wind Energy Council (GWEC), "Annual market update 2012," Global Wind Report, online: http://www.gwec.net.

[2] Global Wind Energy Council (GWEC), "Global wind energy outlook 2012," online: http://www.gwec.net.

[3] Kayikci M. and Milanovic J. V., "Reactive power control strategies for DFIG-based plants," IEEE Transactions on Energy Conversion, 2007, 22, (2), pp. 389 - 396

[4] Sun T., Chen Z., and Blaabjerg F., "Transient stability of DFIG wind turbines at an external short circuit fault," Wind Energy, 2005, 8, (3), pp. 345-360

[5] Tan K. and Islam S., "Optimum control strategies in energy conversion of PMSG wind turbine system without mechanical sensors," IEEE Transactions on Energy Conversion, 2004, 19, (2), pp. 392-399

[6] Chinchilla M., Arnaltes S., and Busgos J. C., "Control of permanent magnet synchronous generators applied to variable speed wind energy systems connected to the grid," IEEE Transactions on Energy Conversion, 2006, 21, (1), pp. 130-135

[7] Muyeen S. M., Takahashi R., Murata T., and Tamura J., "Transient stability enhancement of variable speed wind turbine driven PMSG with rectifier-boost converter-inverter," in Proc. of ICEM, Portugal, Sep. 6-9, 2008.

[8] Echenique E., Dixon J., Cardenas R., and Pena R., "Sensorless control for a switched reluctance wind generator, based on current slopes and neural networks," IEEE Transactions on Industrial Electronics, 2009, 56, (3), pp. $817-825$

[9] Hasanien Hany M., and Muyeen S. M., "Speed control of grid-connected switched reluctance generator driven by variable speed wind turbine using adaptive neural network controller", Electric Power Systems Research, Elsevier, 2012, 84, (1), pp. 206-213

[10] Ribrant J. and Bertling L. M., "Survey of failures in wind power systems with focus on Swedish wind power plants during 1997-2005," IEEE Transactions on Energy Conversion, 2007, 22, (1), pp. 167173

[11] Visioli A., "Tuning of PID controllers with fuzzy logic," IEE Proc. Control Theory Applications, 2001, 148, (1), pp. 1-8

[12]Li Y., Ang K. H., and Chong G.C.Y., "PID control system analysis and design, problems, remedies, and future directions," IEEE Control System Magazine, 2006, 26, (1), pp. 32-41

[13]Rubaai Ahmed, and Young Paul, "EKF-based PI-/PD-like fuzzy-neural-network-controller for brushless drives," IEEE Transactions on Industry Applications, 2011, 47, (6), pp. 2391-2401

[14] Lennartson B., and Kristiansson B., "Evaluation and tuning of robust PID controllers," IET Control Theory and Applications, 2009, 3, (3), pp. 294-302

[15]Li X.H., Yu H.B., Yuan M.Z., and Wang J., "Design of robust optimal proportional-integral-derivative controller based on new interval polynomial stability criterion and Lyapunov theorem in the multiple parameters' perturbations circumstance," IET Control Theory and Applications, 2010, 4, (11), pp. $2427-2440$

[16] Devaraj D., and Selvabala B., "Real-coded genetic algorithm and fuzzy logic approach for real-time tuning of proportional-integral-derivative controller in automatic voltage regulator system," IET Generation, Transmission, and Distribution, 2009, 3, (7), pp. 641-649

[17] Gaing Zwe-Lee, "A particle swarm optimization approach for optimum design of PID controller in AVR system," IEEE Transactions on Energy Conversion, 2004, 19, (2), pp. 384-391

[18] Hasanien Hany M., "Design optimization of PID controller in automatic voltage regulator system using Taguchi combined genetic algorithm method", IEEE Systems Journal, 2013, 7, (4), pp. 825-831

[19] Hasanien Hany M. and Muyeen S. M., "Design Optimization of Controller Parameters used in Variable-Speed Wind Energy Conversion System by Genetic Algorithms", IEEE Transactions on Sustainable Energy, 2012, 3, (2), pp. 200-208

[20] Hasanien Hany M., and Muyeen S. M., "A Taguchi approach for optimum design of proportionalintegral controllers in cascaded control scheme", IEEE Transactions on Power Systems, 2013, 28, (2), pp. 1636-1644

[21] Ozeki K. and Umeda T., "An adaptive filtering algorithm using an orthogonal projection to an affine subspace and its properties," Electron.Commun. Japan, 1984, 67-A, (5), pp. 19-27

[22] Ni Jingen, and Li Feng, "Efficient implementation of the affine projection sign algorithm", IEEE Signal Processing Letters, 2012, 19, (1), pp. 24-26 
[23] Xiao L., Wang Y., Zhang P., Wu M., and Yang J., "Variable regularisation efficient $\mu$-law improved proportionate affine projection algorithm for sparse system identification", Electronics Letters, 2012, 48, (3), pp. 182-184

[24] J.M.Gil-Cacho, , Signoretto, M., Van Waterschoot, T., Moonen, M., and Jensen, S.H., "Nonlinear acoustic echo cancellation based on a sliding-window leaky kernel affine projection algorithm", IEEE Transactions on Audio, Speech, and Language Processing, 2013, 21, (9), pp. 1867-1878

[25] Hasanien Hany M., "Shuffled frog leaping algorithm-based static synchronous compensator for transient stability improvement of a grid-connected wind farm", IET Renewable Power Generation, vol. 8, no. 6, pp. 722-730, August 2014.

[26] Muyeen S.M., Hasanien Hany M., and Tamura J., "Reduction of frequency fluctuation for wind farm connected power systems by an adaptive artificial neural network controlled energy capacitor system", IET Renewable Power Generation, 2012, 6, (4), pp. 226-235

[27] Muyeen S.M., Hasanien Hany M., and Al-Durra Ahmed, "Transient stability enhancement of wind farms connected to a multi-machine power system by using an adaptive ANN-controlled SMES," Energy Conversion and Management, 2014, 78, (2), pp. 412-420

[28] Hasanien Hany M., and Al-Ammar Essam. A., "Dynamic response improvement of doubly fed induction generator based wind farm using fuzzy logic controller", Journal of Electrical Engineering, Slovakia, 2012, 63, (5), pp. 281-288

[29] Ambia M. N., Hasanien Hany M., Al-Durra A., and Muyeen S. M., "Harmony search algorithm-based controller parameters optimization for a distributed-generation system," IEEE Transactions on Power Delivery, 2015, 30, (1), pp. 246-255

[30] Hasanien Hany M., Ali Syed Q., and Muyeen S.M.,"Wind generator stability enhancement by using an adaptive artificial neural network controlled superconducting magnetic energy storage", in the proceeding of International Conference on Electrical Machines and Systems, ICEMS, 21-24 October 2012, Sapporo, Japan.

[31] Hany M. Hasanien and S.M. Muyeen, "Particle swarm optimization-based superconducting magnetic energy storage for low-voltage ride-through capability enhancement in wind energy conversion system", Electric Power Components and Systems, 2015, 43, (11), pp. 1278-1288

[32] Muyeen S.M., Takahashi R., Murata T., and Tamura J., "Control strategy for HVDC interconnected DC-based offshore wind farm", in Proc. of ICEMS, Japan, 2009.

[33] Muyeen S. M., Tamura J., and Murata T., "Stability Augmentation of a Grid-connected Wind Farm", Springer-Verlag London, ISBN 978-1-84800-315-6, October 2008.

[34] Slootweg J. G., S. W. H. De Hann, Polinder H., Kling W. L., "General Model for Representing Variable Speed Wind Turbines in Power System Dynamic Simulations," IEEE Transactions on Power System, 2003, 18, (1), pp. 144-151

[35] K. Paul Thomas, and Ogunfunmi T., "On the convergence behavior of the affine projection algorithm for adaptive filters," IEEE Transactions on Circuits and Systems, 2011, 58, (8), pp. 1813-1826

[36] Paulo S.R. Diniz, "Adaptive filtering algorithms and practical implementation," Springer Science+Business Media, LLC, New York, USA, 2008.

[37] PSCAD/EMTDC Manual, Manitoba HVDC Research Center, 1994. 